Within the last week of the ceremony the young men have to undergo another and more severe ordeal. In a secluded spot amongst the hills the old men, who have gone cut in charge of them, make a large fire of logs. When these have burned down, and the red-hot ashes remain, green boughs of Eucalyptus are thrown on the fire, and on these the young men have to lie down in the heat and stifling smoke until they receive permission from the old men to get up.

Finally, on the last night the $\mathrm{me}_{\mathrm{x}_{x}}$ all congregate around a sacred pole which has been erected close by the Parra, and here, all night long, the old men decorate the backs and chests of the younger men with designs, often very elaborate and distinctive, of the various totems. A man is not of necessity-in fact, very seldom is-painted with the design of his own totem. All night long the women remain awake and active in their camp across the river, where again they make two fires in shallow pits, but this time closely side by side.

Before sunrise the decorated men gather together at the base of the sacred pole, "the head man of the ceremony .breaks through the Parra mound, and across the opening thus formed the old men lead their charges, all walking in single file and holding one another's hands. In perfect silence the string of painted men pass from the Engwurra ground across the bed of the creek, and so on to the women's camp, where they form a group, and halt some fifty yards away from the women, who stard behind their fires, which are now giving off dense clouds of smoke from green gum boughs.

Then each old man takes the younger ones under his charge, and with them runs up to the fires. The Bultharra and Panunga men go to the fire made by the Purula and Kumarra women, and vice vers $\hat{a}$, kneeling upon it while the women press them down with their hands upon the men's shoulders. When all have been upon the fires, the old men and the newly-made Urliara cross the river-bed again to the Engwurra ground, and sit around the sacred pole. The fire ceremonies are now complete, but as yet the younger men may not speak to their apmuirra, but must remain out in the bush. After a length of time, varying from two weeks to perhaps six months, each young man brings in a present of food called Chowarilya to his apmürra man, when a sacred ceremony is performed, at the close of which the mouths of the old and young men who are present are touched either with the food brought in, or with some object which has been used in the ceremony, and the ban of silence is removed.

\section{PROFESSOR NEWCOMB ON THE DISTANCES OF THE STARS.}

THE problem of the distances of the stars is of peculiar interest in connection with the Copernican system. The greatest objection to this system, which must have been more clearly seen by astronomers themselves than by any others, was found in the absence of any apparent parallax of the stars. If the earth performed such in immeasurable circle around the sun as Copernicus maintained, then, as it passed from side to side of its orbit, the stars outside the solar system must appear to have a corresponding motion in the other direction, and thus to swing back and forth as the earth moved in one and the other direction. The fact that not the slightest swing of that sort could be seen was, from the time of Ptolemy, the basis on which the doctrine of the earth's immobility rested. The difficulty was simply ignored by Copernicus and his immediate successors.

An indication of the extent to which the difficulty thus arising was felt is seen in the title of a book published by Horrebow, the Danish astronomer, some two centuries ago. This. in. dustrious observer, one of the first who used an instrument resembling our meridian transit of the present day, determined to see if he could find the parallax of the stars by observing the intervals at which a pair of stars in opposite quarters of the heavens crossed his meridian at opposite seasons of the year. When, as he thought, he had won success, he published his observations and conclusions under the title of "Copernicus Triumphans." But, alas! the keen criticism of his contemporaries showed that what he supposed to be a swing of the stars from season to season arose from a minute variation in the rate of his clock, due to the different temperatures to which it was exposed during the day and the night. The measurement of the distance

1 Extracted from an address given by Prof. Simon Newcomb at the dedication of the Flower Observatory, University of Pennsylvania, May 12 . even of the nearest stars evaded astronomical research, until Bessel and Struve arose in the early part of the present century.

On some aspects of the problem of the extent of the universe light is being thrown even now. Evidence is gradually accumulating which points to the probability that the successive orders of smaller and smaller stars, which our continually increasing telescopic power brings into view, are not situated at greater and greater distances, but that we actually see the boundary of our universe. This indication lends a peculiar interest to various questions growing out of the motions of the stars. Quite possibly the problem of these motions will be the great one of the future astronomer. Even now it suggests thoughts and questions of the most far-reaching character.

I have seldom felt a more delicious sense of repose than when crossing the ocean during the summer months I sought a place where I could lie alone on the deck, look up at the constellations, with Lyra near the zenith, and, while listening to the clank of the engine, try to calculate the hundreds of millions of years which would be required by our ship to reach the star a Lyræ if she could continue her course in that direction without ever stopping. It is a striking example of how easily we may fail to realise our knowledge when I say that I have thought many a time how deliciously one might pass those hundred millions of years in a journey to the star $a$ Lyræ, without its occurring to me that we are actually making that very journey at a speed compared with which the motion of a stearnship is slow indeed. Through every year, every hour, every minute, of human history from the first appearance of man on the earth, from the era of the builders of the Pyramids, through the times of Cæsar and Hannibal, through the period of every event that history records, not merely our earth, but the sun and the whole solar system with it, have been speeding their way towards the star of which I speak on a journey of which we know neither the beginning nor the end. During every clock-beat through which humanity has existed it has moved on this journey by an amount which we cannot specify more exactly than to say that it is probably between five and nine miles per second. We are at this moment thousands of miles nearer to $a$ Lyræ than we were a few minutes ago when I began this discourse, and through every future moment, for untold thousands of years to come, the earth and all there is on it will be nearer to $\alpha$ Lyre, or nearer to the place where that star now is, by hundreds of miles for every minute of time come and gone. When shall we get there? Probably in less than a million years, perhaps in half a million. We cannot tell exactly, but get there we must if the laws of nature and the laws of motion continue as they are. To attain to the stars was the seemingly vain wish of the philosopher, but the whole human race is, in a certain sense, realising this wish as rapidly as a speed of six or eight miles a second can bring it about.

I have called attention to this motion because it may, in the not distant future, afford the means of approximating to a solution of the problem already mentioned, that of the extent of the universe. Notwithstanding the success of astronomers during the present century in measuring the parallax of a number of stars, the most recent investigations show that there are very few, perhaps hardly more than a score of stars of which the parallax, and therefore the distance, has been determined with any approach to certainty. Many parallaxes, determined by observers about the middle of the century, have had to disappear before the powerful tests applied by measures with the heliometer; others have been greatly reduced, and the distances of the stars increased in proportion. So far as measurement goes, we can only say of the distances of all the stars, except the few whose parallaxes have been determined, that they are immeasurable. The radius of the earth's orbit, a line more than ninety millions of miles in length, not only vanishes from sight before we reach the distance of the great mass of stars, but be. comes such a mere point that, when magnified by the powerful instruments of modern times, the most delicate appliances fail to make it measurable. Here the solar motion comes to our help. This motion, by which, as I have said, we are carried unceasingly through space, is made evident by a motion of most of the stars in the opposite direction, just as, passing through a country on a railway, we see the houses on the right and on the left being left behind us. It is clear enough that the apparent motion will be more rapid the nearer the object. We may, therefore, form some idea of the distance of the stars when we know the amount of the motion. It is found 
that, in the great mass of stars of the sixth magnitude, the smallest visible to the naked eye, the motion is about three seconds per century. As a measure thus stated does not convey an accurate conception of magnitude to one not practiced in the subject, I would say that, in the heavens, to the ordinary eye, a pair of stars will appear single unless they are separated by a distance of 150 or 200 seconds. Let us then imagine ourselves looking at a star of the sixth magnitude, which is at rest while we are carried past it with the motion of six or eight miles per second which I have described. Mark its position in the heavens as we see it to-day; then let its position again be marked 5000 years hence. A good eye will just be able to perceive that there are two stars marked instead of one. The two would be so close together that no distinct space between them could be perceived by unaided vision. It is due to the magnifying power of the telescope, enlarging, such small apparent distances, that the motion has been determined in so small a period as the 150 years during which accurate observations of the stars have been made.

\section{PRIMITIVE METHODS OF DRILLING.}

"A STUDY of the Primitive Methods of Drilling" is the title of a monograph by Mr. J. D. McGuire, in the recentlypublished Report of the United States National Museum (1894). The paper covers I 25 pages of the Report, and is fully illustrated, in addition to which there are numerous references to books of travel among peoples living under the most primitive conditions. The author of the paper verified his opinions during the progress of the work by experiments in a laboratory fitted up for the purpose in the United States National Museum.

The paper discusses the various ways by which holes are bored in material, ranging from the softest to the hardest known, with such implements as were possessed by different peoples throughout the age of stone, and well through that of metal. The implements employed in performing the work were chiefly such as are on deposit in the Museum, the collections of which, especially from the North American tribes of Indians, are very rich. Yet the author has not hesitated, where circumstances warranted, to seek further afield for examples, notably in the concluding portion of the paper, where he describes a heretofore

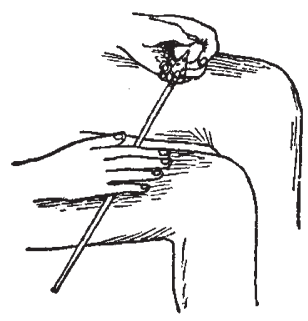

F1G. 1. - Horizontal drilling. unrecognised drill, which frequently appears on the bases of royal seats among Egyptian antiquities. The act of cutting a hole through stone, or other substance, is shown to be a much simpler process than archæologists have heretofore supposed. The author has shown by specimens, and by quotations, that man, from the first time of which we have evidence of his existence, perforated with apparent ease material, such as shell or bone or ivory, and that to do this required nothing more than a stick or a stone with a little sand.

It is shown that early in the Lake period of Switzerland, hollow cylinder of metal was often employed in boring stone axes, and the same conditions have existed from very early times in the history of the most ancient nations of which we have any records.

The seals of Mesopotamia, as well as the earliest intaglios, it is asserted, were bored with the drill and wheel from a period ante-dating the Christian era by thousands of years. The author shows that the American Indian, at the time of the discovery of the country, employed only the simple shaft-drill revolved between the extended palms of the hands, a method yet in use among the most primitive peoples in producing fire. The same implement, revolved horizontally upon the thigh, is illustrated in Fig. I, by which means any of the simpler holes found in the earliest antiquities may be readily and quickly reproduced.

The "Bow Drill" (Fig. 2) is represented in the monograph as it has been employed by various races, ancient and modern, showing the manner of working it, and the differences in shape of the bow and shaft of the drill. The author calls attention to Fig. 3, which he says is the drill bow of ancient Egypt carried in sacred processions as an emblem of ceremony.

Fig. 4 is a drill of a complicated character used by certain California tribes, and appears to be an aboriginal American outgrowth of the "Pump Drill," which was imported into the country from Europe or Asia in modern times. The author illustrates what he designates as a "Top Drill" (Fig. 5), worked by means of a single strap and head-piece, which was developed in the course of his experiments. While in itself this drill is not claimed to be of any great value, it did lead to most interest. ing developments, the principle of which is, among other things, recognised in the Hindu statue of Samudra Mutu (the third incarnation of Vish. nu). This again, in its turn, led to the recognition of the "Disc Drill" with double string, shown in Fig. 6, a most common glyph among early and late Egyptian antiquities known as the "S. S. M." or "Sam," which is by some authors thought to be "an altar typical of the Upper and Lower Nile joined under a single Pharaoh." Such a drill was set up in the Museum labora. tory, and was found to work with perfect ease, and to be capable of producing any of the holes met with among the bored monumental stones of Egypt. The number of persons who, upon occasion, might be employed at the same time in working this drill, is unlimited; though probably not more than four would be required at any one time.

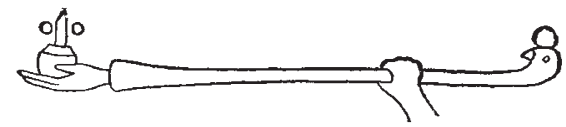

FIG. 3.-Ancient Egyptian Drill Bow.

The author not only tested the different stone points employed in boring stone and softer substances, but used the stone points themselves with sands of differing hardness upon different stones. Metal points to drills, as well as metal cylinders, were tested as to their cutting properties. Points of all kinds were experimented with, demonstrating that the sharp sand and wood points are capable of cutting a hole through any material, provided it was not harder than the sand. The paper shows the different characters of holes met with in objects of a prehistoric period, or by people in a low stage of mechanical development, and describes how such holes were made.

In most instances the exact number of revolutions per minute of each separate drill was recorded, and the character of cutting material was noted ; the results were in every instance uniform. The velocity of revolution and hardness of the sand determined with mathematical accuracy the time required to drill a hole through any given material.

The striæ noticed upon the cores left in some holes bored in stone in Egypt had led distinguished Egyptologists to believe that the Egyptians possessed the diamond drill, with diamonds not only set in the lower edge of the cylinder, but on the outer and inner sides as well. Mr. McGuire's experiments have demonstrated that with such a drill as represented in Fig. 6, a hole of almost any diameter may be made through the hardest stone, and that the marks left on the interior of the drill-hole, or exterior of the core in the hole, is governed entirely by the hardness of the sand and size of its grains. The time requisite

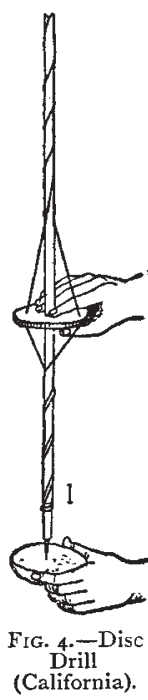
to perforate any material is shown to be but a fraction of what has been heretofore supposed necessary.

The paper proves the value of a study of the technology of archæology, and its necessity in any intelligent study of primitive implements. The manufacture of any product of ancient man

NO. I 44I, VOL. 56] 